\title{
New Records of Hypoxylon Species from India
}

\author{
K.M. Bhise and P.G. Reddy* \\ Department of Botany.R.B.N.B. College, Shrirampur, Dist-Ahmednagar-413709. \\ * Department of Botany. Padmashri Vikhe Patil College, Pravaranagar,Dist- \\ Ahmednagar-413713
}

\begin{abstract}
The present paper describes three lignicolous species of Hypoxylon viz., $H$. salicicola, $H$.subalbum and $H$. vinosopulvinatum collected from Bhandardara, Ghatghar and Vrudheshwar forest in the Western ghat regions of Ahmednagar district in Maharashtra state are described and reported as new to India. All the Specimens are deposited at Department of Botany P.V.P.College, Pravaranagar (Loni).
\end{abstract}

Keywords: Hypoxylon, Stroma,, Perithecia, Asci, Ascospores.

\section{Introduction}

The Western Ghats is one of the mega-biodiversity hot spot regions in India. Bhandardara, Harishchandragadh, Kalsubai and Ghatghar regions dominated with deciduous and semi-evergreen forests that found lying in the ranges of Sahyadri mountain and form a part of Western Ghats in Ahmednagar district of Maharashtra state. These areas are also famous for the rich diversity of fungal flora.

\section{Study Area (Bhadardara region)}

The area under the study includes 235 remotest villages, of which 100 villages belong tribal populace as a major group, of Ahmednagar district of Maharashtra.These villages are considered to be the drought prone regions. Total population of the study area is 12 sq.miles. 


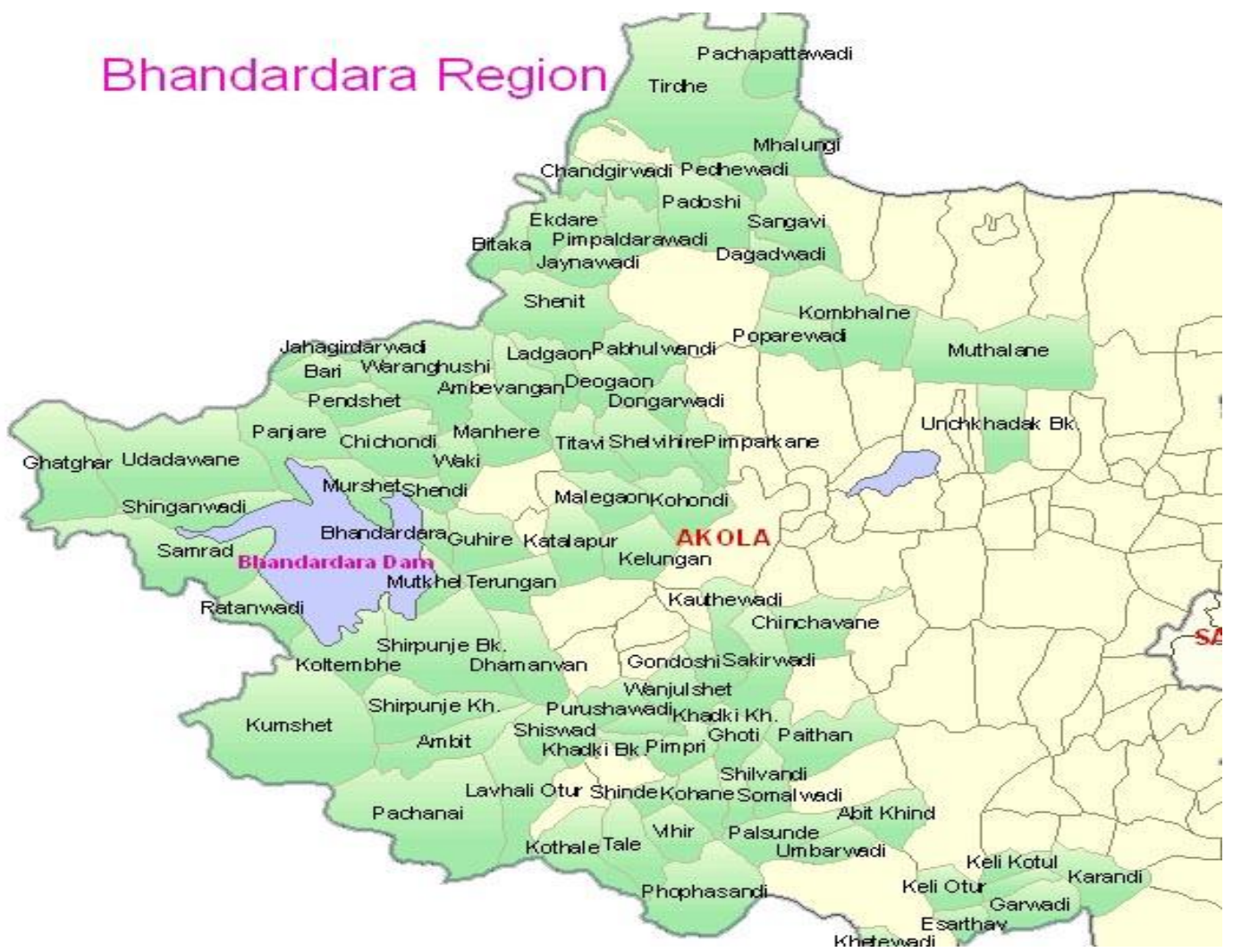

Figure 1: Study area- Bhadardara region

\section{Materials and Methods}

Specimens collected on dry fallen twigs from forest in Bhandardara, Harishchandragadh, Kalsubai and Ghatghar were initially examined under stereoscopic binocular microscope to know the position, type and other features of ascocarp, then sectioned and mounted in lactophenol medium to observe the characters of Perithecia, asci and ascospores. The specimens were identified following Ainsworth, et.al. (1973), Miller (1961), Dennis (1978), Jamaluddin, et .al. (2004).

\section{Hypoxylon salicicola Gramno.}

Ostiolar opening umblicate, Stromata other than whitish on surface, when dehiscent, smooth or with inconspicuous coil like ornamentation, Stromatal pigments yellow, orange to brownish orange, stromatal surface golden- brown. Asci cylindrical, 8 spored, measures 40-45 X 8-9 $\mu \mathrm{m}$. Ascospores uniseriate, 
elliptic-fusiform to bean shaped with one flattened side, measures 7-10 X 3$4.5 \mu \mathrm{m}$. dark brown, with one oil droplet.

Gramno (1999) described this fungus from Norway. Morphological characters of present collection resemble with the original description. It is collected on Nyctanthes arbor-tritis L.From Bhandardara forest. It is new record to ascomycete's mycoflora of India.

\section{Hypoxylon subalbum Ju, Rogers \& Hsieh.}

Stromata pulvinate, surface dull white with black ostiolar areas, black immediately beneath surface and between perithecia, tissue below perithecial layer inconspicuous. Perithecia spherical 1 to $0.5 \mathrm{~mm}$ diam. Ostiole with inconspicuous umblicate ostiolar openings. Asci cylindrical, 8 spored, measures 65-80 X 10-15 $\mu \mathrm{m}$. Ascopores dark brown, unicellular ellipsoid-inequilaterally with narrowly to broadly round ends, measures 9-12 X 6-8 $\mu \mathrm{m}$, Perispore with very conspicuous coil-like ornamentation, epispore smooth.

It differs from all other species of Hypoxylon in having white Stromata, in dimensions of ascospores, in ornamentation of perispores or in length of ascospores germ slit or in black ostiole. Ascospores with a short germ slit, and lack of stromatal pigment. The present specimen is similar in characters described by Ju, et.al. (2004).It is collected on Delonix regia from Vrudheshwar forest area. The characters of present specimen agree with the description. It is reported first time from India.

\section{Hypoxylon vinosopulvinatum $\mathrm{Ju}$, Roger \& Hsieh.}

Stromata pulvinate, discrete or confluent, with conspicuous perithecial mounds, surface brown, vinaceous, dull with purplish-brown granules, tissue below perithecial layer inconspicuous. Perithecia obovate, 0.1-0.2 mm dia. X 0.2-0.3 $\mathrm{mm}$ high. Ostiole lowers than stromatal surface, with umblicate ostiolar openings, often overlain with white substance. Asci cylindrical, with 8 ascospores, uniseriate, measures 120-145 X 6.5-7.5 $\mu \mathrm{m}$, the spore bearing parts 70-80 $\mu \mathrm{m}$ long, with apical ring bluing with Melzer`s iodine reagent ,discoid. Ascospores dark brown, unicellular, ellipsoid-inequilaterally, with narrowly rounded ends, measures 10-15 X 5-7 $\mu \mathrm{m}$, with straight germ slit spore-length on convex side, smooth, thin, epispore smooth.

Present specimen is similar in characters described by Ju, et.al. (2004). It is collected on Erythrina indica From Ghatghar forest. It's a new record to the lignicolous ascomycetes of India. 


\section{Acknowledgements}

The authors are thankful to Dr. M. S. Patil (Retd.) Head, Department of Botany, Shivaji University,Kolhapur for confirming the identification of species. Thanks are due to the help from U.G.C. for providing financial assistance under the faculty improvement program and to the Principal, R.B.N.B. College, Shrirampur for sanctioning the study leave.

\section{References}

[1] G.C. Ainsworth, F.K.Sparrow and A.C.Sussman. The Fungi. In advanced treatise. Vol: IV A Academic press. London. A Taxonomic Review with keys (1973) 307p.

[2] R.W.G. Dennis. British Ascomycetes, J. Cramer 3rd Edition. J. Cramer Vaduz Revised XXVI. (1978) pp. 1-585.

[3] A. Gramno.Morphotaxonomy and Chorology of the genus Hypoxylon (Xylariaceae) in Norway. Sommerfeltia 26 (1999) 1-81.

[4] S. Jamaluddin, M.G. Goswami, and B.M. Ojha. Fungi of India.19892001.Host index and Addenda. Scientific Publishers (India) Jodhpur (2004) 326p.

[5] Y.M. Ju, J.D. Rogers and H.M.Hsieh. New Hypoxylon.sp.and notes on some names associated with or related to Hypoxylon. Mycologia.96 (1) (2004) 154-161.

[6] J.H. Miller. A monograph of the World species of Hypoxylon.Univ. Georgia Press, Athens, (1961) pp.158. 